\title{
Percussions of Epigenetics on Mood Disorders; Is It Really A Charm or Just A Propaganda??!!!
}

\section{Eman Ahmed Zaky*}

Department of Pediatrics, Ain Shams University, Cairo, Egypt

*Corresponding author: Prof. Zaky EA, Professor of Pediatrics and Head of Child Psychiatry Unit, Department of Pediatrics, Faculty of Medicine, Ain Shams University, Cairo, Egypt, Tel: 00201062978734; E-mail: emanzaky@med.asu.edu.eg

Received date: September 29, 2017; Accepted date: October 10, 2017; Published date: October 17, 2017

Copyright: (c) 2017 Zaky EA. This is an open-access article distributed under the terms of the Creative Commons Attribution License; which permits unrestricted use; distribution; and reproduction in any medium; provided the original author and source are credited.

\begin{abstract}
The interaction between environmental factors and genetic vulnerability plays a major role in the development of mood disorders. Episodes of bipolar disorder could be considered as the outcome of the battle between stress and the individual's ability to cope with; a fact that proposes a role of epigenetics in its pathogenesis and pathophysiology. Although the molecular studies on methylation of DNA and histone modification in cases of bipolar disorder are still inadequate but the role of stress in developing the disorder and the therapeutic efficacy of mood stabilizers in controlling its episodes highlight the potential influence of epigenetic variation on its occurrence. Limited availability of human brain tissue for conducting researches represents a great obstacle in replicating the findings on animal models of mood disorders in humans as humans do differ from animals in their response to environmental factors whether on the subcellular, cellular, organ, or individualistic levels; nevertheless some ongoing research on DNA methylation seems to be very promising in settling the impact of epigenetics on the development of bipolar disorder with a potential role in empowering psychiatrists in helping their patients and controlling its episodes.
\end{abstract}

Keywords: Epigenetics; Mood disorders; Bipolar disorder; CHARM; DNA methylation; Histone modification; Genomic imprinting; Stress; Hypothalamic pituitary adrenal axis

\section{Introduction}

Bipolar disorder is a disease with an intermittent course in which periods of depression alternate with periods of euphoria (elated mood). There are solid evidences which show that stress is a major trigger in firing its episodes; a fact that proposes an epigenetic link with its pathogenesis and pathophysiology. On the other hand, parent of origin specific inheritance researches as well as linkage analysis indicate a potential role of genomic imprinting in the development of bipolar disorder. Up to date; molecular studies on methylation of DNA and histone modification in cases of bipolar disorder are still inadequate but the role of stress in developing the disorder and the therapeutic efficacy of mood stabilizers in controlling its episodes highlight the influence of epigenetic variation on the occurrence of such disorder [1-4].

\section{What is Epigenetics?}

Epigenetics with the Greek prefix epi; meaning over, outside of, or around, is concerned with studying the genetic effects which are not encoded in the DNA sequence of an organism but may result from external factors that switch genes on and off and hence affecting the cellular gene expression. Such effects may or may not be inherited but using the terminology "epigenetics" to describe heritable processes is a matter of debate [4-8].

Historically, epigenetics has started to be known in 1942 when Conrad Waddington used it to describe how the interaction between hereditary susceptibility and environmental factors can affect the outcome phenotype; biologically and or clinically $[9,10]$. In the pure context of biology, epigenesis means the differentiation of cells from the totipotent state into the different pluripotent embryonic cell lines. Nowadays, epigenetics is an experimental science that tries to explain how environment (nurture) influences biological markers (nature). With the advances in molecular genetics, the term "epigenetics" has been used to clearly identify the cellular heritable information that is not related to gene sequence but rather to gene expression and how such information is affected by the surrounding ecological factors [2-4,11].

In the field of studying human behavior and mental disorders, epigenetics aims at providing a scientific background for recognizing in what way the expression of genes is affected by the individual experience and other surrounding environmental factors like dietary constituents and toxins exposure to lead to a specific behavior phenotype, cognitive abilities, personality, and mental health status $[12,13]$.

\section{Epigenetic Mechanisms}

Mechanisms that produce epigenetic effects include DNA methylation and histone modification; both mechanisms affect the way of gene expression without alteration of the DNA sequence. Alteration of gene expression can also occur via the action of repressor proteins which can bind to silencing regions of the DNA $[14,15]$.

Several reports have linked schizophrenia and mood disorders with DNA rearrangements which include the DNMT genes. DNMT1 is specifically overexpressed in gamma aminobutyric acid (GABA)-ergic interneurons of schizophrenic brains while hypermethylation has been shown to reduce expression of Reelin; a protein which is needed for normal neurotransmission, formation of memory, and synaptic plasticity, in brain tissues of schizophrenia sufferers and patients with bipolar disorder and psychosis $[16,17]$. 
Page 2 of 3

On the other hand, epigenetic inheritance of depression associated phenotypes has been shown in an animal study in which paternal stress induced traits were transmitted across generations with involvement of small noncoding RNA signals which were passed through the male germline [18].

\section{CHARM is Here}

A microarray (Chip) has been used by a group of researchers at John Hopkins Epigenetic Center as one of the tools in investigating the influence of epigenetic markers on bipolar disorder as well as depression and stress. Feinberg; the pioneer in developing that tool, called it CHARM after Baltimore that is named "the Charm city"; the place at which John Hopkins Epigenetic Center exists. When such microarray was used in studying human or animal DNA, it has been found that it can detect methylation in any of its genes at the same time. Consequently, such tool has paved the way in front of promising researches studying the percussions of epigenetics on mood disorders; its etiology, pathogenesis, and treatment [3].

\section{Stress}

Poor care during infancy whether in human or animal studies was associated with epigenetic changes which resulted in long term impairments of neglect [19-21]. Interestingly; frequent liking in rats resulted in a long term decrease in stress response assessed both behaviorally and biochemically by measuring elements of the Hypothalamic Pituitary Adrenal Axis (HPA). In addition, reduced DNA methylation of the glucocorticoid receptor gene was found in offspring which experienced frequent liking; such finding was striking as glucocorticoid receptor plays a crucial role in regulating the HPA. It is worthy to mention that the opposite was reported in offspring which experienced infrequent liking and the reported epigenetic changes were reversible when pups were switched [19]. These results were supported by other studies which used drugs to increase or decrease methylation [20].

In humans, it has been shown that prenatal exposure to depressed/ anxious mood was associated with elevated levels of DNA methylation of the glucocorticoid receptor gene with increased HPA axis response to stress and these findings were independent of the use of medications to treat maternal depression [19]. Recently, an association between maternal glucocorticoid receptor and maternal neural activity in response to mother infant interactions has been proven on video [22].

\section{Bipolar Disorder}

The link between epigenetic changes and bipolar disorder is controversial [23]. In one study, decreased methylation of a gene promotor of the prefrontal lobe membrane bound catechol-O-methyl transferase (COMT) was discovered in post mortem brain tissues of patients with bipolar disorder. COMT is the enzyme which is responsible for synaptic dopamine metabolism; this means that the reported promotor hypomethylation might be the cause of increased expression of the enzyme with enhanced breakdown of dopamine in the brain which represents a risk factor for the development of bipolar disorder [16]. However, such results were not replicated in another study with similar setting [24].

\section{Major Depressive Disorder}

Neuro-scientifically, the etiology of major depressive disorder (MDD) is not clearly defined. However, epigenetic alteration that results in changes of the level of expression of the glucocorticoid receptor gene and its impact on the HPA stress system may be helpful in trying to understand what is behind the occurrence of MDD [25].

Interestingly, over activation of the HPA stress axis has been shown to be associated with down regulation of brain derived neurotrophic factor (BDNF) in animal models [26,27]. Animal studies on models of depression with induction of stress have also shown direct epigenetic alteration of BDNF [28].

\section{Antidepressant Therapeutic Modalities and Epigenetics}

The effects of antidepressant therapeutic modalities as antidepressant medications and electroconvulsive therapy are thought to be mediated by histone modification on promotor of BDNF gene [23].

\section{Limitations and Future Scope; A Charm or A Propaganda!!!}

Limited availability of human brain tissue for conducting researches represents a great obstacle in replicating the findings on animal models of mood disorders in humans; humans do differ from animals in their response to environmental factors whether on the subcellular, cellular, organ, or individualistic levels. Also, it is not known yet if the epigenetic alterations in blood or non-brain tissues simulate brain changes which necessitate the conduction of more researches on brain tissues $[4,29]$. Furthermore, most of the epigenetic research depends on establishment of correlations and associations; a fact that mandates directing more research aiming at establishing causation [30]. Also, it is wise to carry more research on drugs as many drugs are known to alter the activity of many genes and accordingly can lead to serious side effects [4].

On the other hand, studies of DNA methylation from the same patients suffering from bipolar disorder during the different stages of the disease, from sufferers before and after treating them with mood stabilizers like sodium valproate, from cases before and after exposure to significant stressors, and from animal models of mood disorders induced by stress seem to be very promising in settling the impact of epigenetics on the development of bipolar disorder with a potential role in empowering psychiatrists in helping their patients and controlling its episodes [1-3].

\section{References}

1. http://europepmc.org/articles/PMC2698240

2. Shinozaki G, Hing B, Potash JB (2014) Epigenetics of Bipolar Disorder. Epigenetics in Psychiatry, pp: 265-278.

3. http://abcnews.go.com/Health/Depression/Story?id=4839669\&page=1

4. Miller G (2010) Epigenetics. The seductive allure of behavior epigenetics. Science 329: 24-27.

5. Powledge T (2011) Behavioral epigenetics: How nature shapes nurture. BioScience 61: 588-592.

6. Champagne FA, Mashoodh R (2012) Genes in context: Geneenvironment interplay and the origins of individual differences in behavior. Curr Dir Psychol Sci 18: 127-131.

7. Zhang TY, Meaney MJ (2010) Epigenetics and the environmental regulation of the genome and its function. Annu Rev Psychol 61: 439-466. 
Citation: Zaky EA (2017) Percussions of Epigenetics on Mood Disorders; Is It Really A Charm or Just A Propaganda??!!!. Clin Depress 3: 126. doi:10.4172/2572-0791.1000126

Page 3 of 3

8. Bagot RC, Meaney MJ (2010) Epigenetics and the biological basis of gene $\mathrm{x}$ environment interactions. J Am Acad Child Adolesc Psychiatry 49: 752-771.

9. Waddington $\mathrm{CH}$ (1942) The epigenotype. Endeavoue 1: 18-20.

10. Holliday R (2006) Epigenetics: A historical overview. Epigenetics 1: 76-80.

11. Pennisi E (2001) Behind the scenes of gene expression. Science 293: 1064-1067.

12. Stuffrein-Roberts S, Joyce PR, Kennedy MA (2008) Role of epigenetics in mental disorders. The Australian and New Zealand Journal of Psychiatry 42: 97-107.

13. Erikson E (1968) Identity: Youth and crisis. WW Norton and Company Inc, New York. p. 92.

14. Holliday R (1990) DNA methylation and epigenetic inheritance. Philos Trans R Soc Lond B Biol Sci 326: 329-338.

15. Robertson KD, Wolffe AP (2000) DNA methylation in health and disease. Nat Rev Genet 1: 11-19.

16. Abdolmaleky HM, Cheng KH, Faraone SV, Wilcox M, Glatt SJ, et al (2006) Hypomethylation of MB-COMT promotor is a major risk factor for schizophrenia and bipolar disorder. Hum Mol Genet 15: 3132-3145.

17. Mill J, Tang T, Kaminsky Z, Khare T, Yazdanpanah S, et al. (2008) Epigenomic profiling reveals DNA-methylation changes associated with major psychosis. Am J Hum Genet 82: 696-711.

18. Short AK, Fennell KA, Perreau VM, Fox A, O’Bryan MK, et al. (2016) Elevated paternal glucocorticoid exposure alters the small noncoding RNA profile in sperm and modifies anxiety and depressive phenotypes in the offspring. Transl Psychiatry 6: e837.

19. Masterpasqua F (2009) Psychology and epigenetics. Review of General Psychology 13: 194-201.
20. Szyf M, McGowan P, Meaney MJ (2008) The social environment and the epigenome. Environ Mol Mutagen 49: 46-60.

21. González-Pardo H, Pérez Alvarez M (2013) Epigenetics and its implications for psychology. Psicothema 25: 3-12.

22. http://journal.frontiersin.org/article/10.3389/fpsyg.2015.00690/abstract

23. McGowan PO, Kato T (2008) Epigenetics in mood disorders. Environ Health Prev Med 13: 16-24.

24. Dempster EL, Mill J, Craig IW, Collier DA (2006) The quantification of COMT mRNA in postmortem cerebellum tissue: Diagnosis, genotype, methylation and expression. BMC Med Genet 7: 10.

25. Pariante CM, Lightman SL (2008) The HPA axis in major depression: classical theories and new developments. Trends Neurosci 31: 464-468.

26. Tsankova NM, Berton O, Renthal W, Kumar A, Neve RL, et al. (2006) Sustained hippocampal chromatin regulation in a mouse model of depression and antidepressant action. Nat Neurosci 9: 519-525.

27. Gray JD, Milner TA, McEwen BS (2013) Dynamic plasticity: The role of glucocorticoids, brain-derived neurotrophic factor and other trophic factors. Neuroscience 239: 214-227.

28. Hunter RG (2012) Epigenetic effects of stress and corticosteroids in the brain. Front Cell Neurosci 6: 18.

29. Albert PR (2010) Epigenetics in mental illness: hope or hype? J Psychiatry Neurosci 35: 366-368.

30. Dempster EL, Pidsley R, Schalkwyk LC, Owens S, Georgiades A, et al. (2011) Disease associated epigenetic changes in monozygotic twins discordant for schizophrenia and bipolar disorder. Hum Mol Genet 20: 4786-4796. 